\title{
Optimization of Wear Process Parameters on 17-Cr Ferritic ODS Steel
}

\section{G. Dharmalingam, Prabhukumar Sellamuthu}

\begin{abstract}
The main aim of this article deals with the wear behavior of mechanically alloyed 17-Cr oxide dispersion strengthened (ODS) Ferritic steel consolidated through Vacuum Hot Pressing (VHP) at temperature level of $1170{ }^{\circ} \mathrm{C}$ under pressure level of $60 \mathrm{MPa}$ with 60 minutes as holding time and with rate of cooling of $50{ }^{\circ} \mathrm{C} / \mathrm{min}$ and a vacuum level of $10^{-3} \mathrm{torr}$. The persuade of wear process parameters were investigated based on the load applied, sliding velocity and sliding distance at a temperature of $350^{\circ} \mathrm{C}$ on dry sliding track of 17-Cr Ferritic oxide dispersion strengthened steel (Fe-17Cr-0.35Y $\mathrm{Y}_{2} \mathrm{O}_{3}-1.5 \mathrm{ZrO}_{2}-4 \mathrm{Al}$ (\%wt). Wear test was conducted in a dry atmosphere using a pinon-disc wear testing machine. Wear behavior of 17-Cr Ferritic ODS steel was analyzed by using Taguchi approach. To examine the process parameter during high temperature wear rate analysis of variance and signal to noise ratios were used. During the wear analysis sliding distance was found to be influential parameters of wear rate for 17-Cr Ferritic oxide dispersion strengthened steel succeeded by functional load and sliding velocity. The regression model was found to calculate the rate of wear for 17-Cr Ferritic oxide dispersion strengthened steel.
\end{abstract}

Key words: High temperature wear, 17-Cr ODS ferritic steel Vacuum Hot Pressing (VHP), Taguchi method, analysis of variance (ANOVA), regression model.

\section{INTRODUCTION}

One of the outstanding materials for high temperature application like automobile exhaust valve, nuclear, fast breeder reactors and thermal power plant with a great demand for tribological properties is Ferritic Stainless Steel (FSS). To cater the industrial needs low cost powder metallurgy with appropriate mechanical properties are suited for FSS. The purpose of the current study is to carry out the wear studies on ferritic ODS steel for high temperature applications. FSS were used in the high-temperature environment industrial applications such as exhaust valves of the typical diesel engines, rocket motors, nuclear fuel element spacers, hot extrusion tools, high strength bolts, pump bodies and parts and Jet engines. The structure of FSS is body centered cubic crystal which favor high temperature applications outstanding the properties it processes similar to high tensile, compressive strength, creep resistance, good oxidation resistance ,lower coefficient of thermal expansion, very good high thermal conductivity and good swelling resistance [1,2].

Revised Manuscript Received on December 30, 2019.

* Correspondence Author

G. Dharmalingam*, Research scholar, Department of Mechanical Engineering, Vel Tech Rangarajan Dr. Sagunthala R\&D Institute of science and Technology, Chennai (Tamil Nadu) India.

E-mail: dharma21sona@gmail.com.

Prabhukumar Sellamuthu, Assistant Professor, Department of Mechanical Engineering, Vel Tech Rangarajan Dr. Sagunthala R\&D Institute of science and Technology, Chennai (Tamil Nadu) India.

E-mail: prabhukumar.sellamuthu@gmail.com.

(c) The Authors. Published by Blue Eyes Intelligence Engineering and Sciences Publication (BEIESP). This is an open access article under the CC BY-NC-ND license (http://creativecommons.org/licenses/by-nc-nd/4.0/)

Ambient temperature and High temperature strength are improved by the addition of nano oxide dispersion strengthened (ODS) which inhibits the grain boundary sliding of the FSS [3]. FSS with the addition of ODS consists of superior mechanical properties at high as well as room temperature in addition to swelling resistance compared to austenitic stainless steel (ASS) [4,5].Without the addition of ODS ferritic/martensitic steels are having inferior void swelling and irradiation resistance of neutron. To provide effective barrier for dislocation stabilized nanosized oxide particles were added [6]. High density containing yttrium, zirconium oxide particles ferritic ODS steels are believed as a potential material for nuclear application [7]. Due to the improvement in density and hardness yttria dispersed stainless steel have higher wear resistance than yttria free stainless steel [8]. With the addition of ceramic and metal oxide particles as dispersion materials, sintering parameters are varied to control the grain growth [9]. Tribological properties of steels are improved by the addition of oxides of zirconium and yttrium nano particles [10]. Karak et.al reported the wear behavior of the 25.5Cr (in wt.\%) ferritic ODS steel alloy were dependent on the temperature of the sintering. Maximum resistance to wear was observed depending on the sintering parameters. In this study sintering temperature at $1000{ }^{\circ} \mathrm{C}$ minimum wear rate were observed [11]. Ruiz-Navas, E. M., et al. stated that debris formed were dependent on the speed of the rotating disc for higher loads and sliding velocity, sliding between the pin and disc, promotes the stainless steel, it gives low wear rates due to oxides formation on the wear track [12]. Tuckart, $\mathrm{W}$ et al. stated that mechanism of wear is a form in which metal oxides over the tribo surface $\alpha-\mathrm{Fe}_{2} \mathrm{O}_{3}$ were formed. The oxide particles acts as a lubricant minimizing the metal to metal contact and minimize the wear rate of alloys [13]. Very minimum research article were available for the behavior of wear for ODS containing ferritic steels manufactured through mechanical alloying via powder metallurgy technique, while most of the work is through conventional melting routes. To enhance the wear resistance properties during experiments Trial and error method were used to obtain the local optimal solutions. Statistical estimation was not taken into consideration for individual and interaction factor effects. For a known set of independent parameters can be predicted for wear studies without performing experiments. To derive equation for the prediction of the processes multiple linear regressions were performed, such a study was not conducted elsewhere. The independent variables such as load applied, sliding velocity and sliding distance are accountable for the preferred least wear rate for realistic value in industries is not yet obviously defined. 
The current study focuses on the investigation of wear behavior of weight percentage of chromium (17-Cr wt $\%)$ ferritic ODS steel at high temperature level of $350^{\circ} \mathrm{C}$. 17-Cr (wt \%) ferritic ODS steel developed through powder metallurgy route and consolidated by Vacuum hot pressing (VHP). Minimum wear rate were found out by changeable the sliding distance, sliding velocity and applied load. Therefore after conducting, design of experiments and Taguchi approach a precise study to provide optimum process parameters.

\section{MATERIALA AND METHODS}

Ferritic ODS steel were obtained through mechanical alloying of the powders which were consolidated through VHP.

\section{A. Preparation of ODS Ferritic powder using mechanical alloying}

Theoretical density of $7.450 \mathrm{~g} / \mathrm{cc}$ was obtained for the alloy by zirconia, aluminum and yttria addition to the pre-alloyed $430 \mathrm{~L}$ powders as shown in table 1 . Pre-alloyed 430L powders were secured from SANDVIK $(-22 \mu \mathrm{m}$ the average particle size) which were assessed using mastersizer 3000 (UK) with a purity level of 99\%. The corresponding chemical composition of the mixture is depicted in table 1 which shows the projected composition for this current study. Yttrium (III) and Zirconium oxide powders an average particle size of both the powders $\pm 10 \mu \mathrm{m}$ which were obtained from $\mathrm{M} / \mathrm{s}$ Jiaton, China. Aluminium powders of $-67 \mu \mathrm{m}$ were acquired from Metal Powder Company, chennai, India.

Table 1: Chemical composition of Ferritic steels and its mixtures

\begin{tabular}{|c|c|c|c|c|c|c|c|c|}
\hline $\begin{array}{l}\text { Powder } \\
\text { Grade }\end{array}$ & $\mathrm{Cr}$ & Mn & $\mathrm{Si}$ & $\mathrm{C}$ & $\mathrm{P}$ & S & $\mathrm{Fe}$ & $\begin{array}{c}\text { Theoretical } \\
\text { Density } \\
\text { (g/cc) }\end{array}$ \\
\hline $430 \mathrm{~L}$ & 17 & 0.9 & 0.9 & 0 & 0 & 0 & Bal & 7.7 \\
\hline Alloy & \multicolumn{7}{|c|}{$\left(430 \mathrm{~L}-0.35 \mathrm{Y}_{2} \mathrm{O}_{3}-1.5 \mathrm{ZrO}_{2}-4 \mathrm{Al}\right)$ wt $\%$} & 7.45 \\
\hline
\end{tabular}

The process of mechanical alloying were executed using High energy planetary ball milling (Fritsch Pulversitte PM400 ) under ambient atmosphere in stainless steel vials and balls [14,15]. Ball to powder ratio of 10:1 were used as a operating parameter of planetary ball mill along with a milling speed of $300 \mathrm{rpm}$ and milling time of $20 \mathrm{hrs}$. Process control reagent which avoids combustion during MA of powders were used namely toluene medium. Toluene medium avoids the inter-particle agglomeration due to collision which subsequently leads to particle size reduction. Phase evolution of powders were done using MA for $20 \mathrm{hrs}$ and powders were collected at regular intervals of $0 \mathrm{hr}, 10$ hrs, 15 hrs and 20 hrs respectively to analyze the phase transformation using X-Ray Diffractometer (XRD) with the $\mathrm{Cu} \mathrm{K} \alpha(\lambda=1.542 \AA)$ in a Philips X-pert MPD. The milled powders crystallite size and lattice strain were calculated using Debye's scherrer formula. Scanning electron microscope (SEM) (JOEL/EO) was used to study the powder morphology (accelerating voltage of $15 \mathrm{kV}$ and an operating distance of $11.5 \mathrm{~mm}$ ) of an alloy. Rule of mixtures were applied to calculate the theoretical density which is shown in table 1 . Consolidated powders (20 hours milled) were hot pressed uniaxially using modified vacuum hot pressing machine at a pressure level of $60 \mathrm{MPa}$. The heating rate $10^{\circ} \mathrm{C}$ per min was used with a holding period of $90 \mathrm{~min}$ at a temperature of $1170^{\circ} \mathrm{C}$. The rate of cooling of 50 ${ }^{\circ} \mathrm{C} / \mathrm{min}$ was undertaken after hot pressing. Graphite punch and die with a dimension of $30 \mathrm{~mm}$ diameter and $10 \mathrm{~mm}$ height were used to consolidate the powders to obtain solid component. The level of vacuum was maintained at 10-3 torr throughout the experiment. An electronic precision balance of $0.1 \mathrm{mg}$ was used to measure the weight of the sintered alloy and the density of the alloy was calculated using Archimedes principle. Kalling's reagent $(5 \mathrm{gm} \mathrm{CuCl} 2+$ $100 \mathrm{cc} \mathrm{HCl}+100 \mathrm{cc}$ Ethyl alcohol) is used as an etchant for the polished hot pressed alloy after which it was examined under an optical microscope (Metscope -I), Chennai Metco Pvt. Ltd., India. SEM-EDS were taken for the pin alloy. Transmission electron microscope (TEM) study was carried out on INCA Xsight-JEOL JEM-2100 operated at $200 \mathrm{kV}$. For Dimpling were used Gatan moel 656 with subsequent ion milling of Gatan moel 691 were used for the preparation of TEM alloy. To measure the hardness of the hot pressed alloy Rockwell hardness tester (A-scale) were used, with a load of $60 \mathrm{kgf}$, a dwell time of $10 \mathrm{~s}$ and indenter diamond. Also for hot pressed alloy nano-indentation test were performed using standard nano-indentation hardness (TriboIndenter with Multi mode scanning Nano Probe microscope, Russia) with a Berkovitz indenter at $200 \mathrm{mN}$ load. From nano indentation test hardness value were measured on an average of 20 points and precision was made sure with a repetition of 3-4 times in similar locations.

\section{B. Wear test}

The pin on disc wear testing machine were used to conduct the wear tests.Throughout the wear test experiment the temperature level were maintained at $350^{\circ} \mathrm{C}$. The material of the disc ASSAB 88 tool steel is used as a counterpart material with a hardness of 68 HRA against the pin. Wear behavior of pin is studied using this experiment. For every experimental condition for wear test which were experimented as per ASTM G99 standards and also simulated using L9 Taguchi orthogonal array. Input-Output data of the experiments were shown in table 3. Figure 1 \& 2 shows the pin with dimensions of $8 \mathrm{~mm}$ diameter and 55 $\mathrm{mm}$ height with its counterpart disc. Emery papers with different grades of 400, 600, 800, 1000 and 1200 were used to polish the end faces of pin and disc surface on an automated Chennai METCO double disc polishing machine. Surface roughness of the disc and pin was roughly about 1 $\mu \mathrm{m}$. The process of polishing the pin and disc enabled an uniform contact between the both parts. Acetone was used as cleaning reagent for both the disc and pin after each trial. Further the analogous weights were calculated in a digital balance with accuracy level of $0.1 \mathrm{mg}$. Standard formula shown in equation 3 was used to calculate the wear rates.[16]

Published By:

Blue Eyes Intelligence Engineering \& Sciences Publication 




Fig .1 Wear test alloy Pin on disc

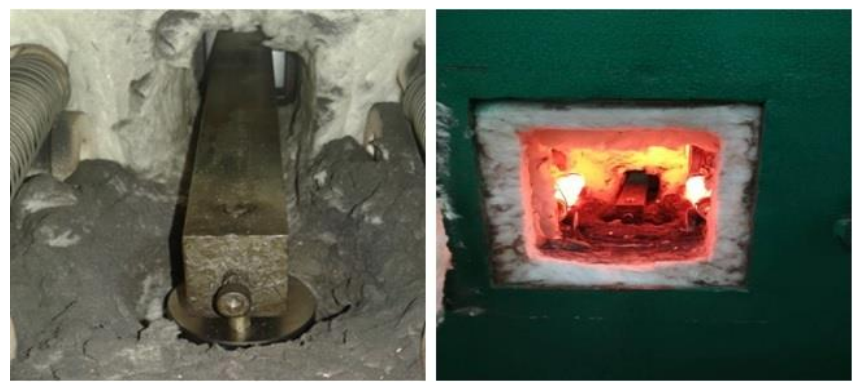

Fig .2 Pin and disc loaded condition in furnace

\section{Taguchi method for the optimization of process parameter for 17Cr Ferritic ODS steel}

For a limited number of runs for experimental studies a successful tool known as Taguchi method is used as a process parameter optimization. Taguchi method was used to reduce the operating cost of the experiments and the factors influencing it to attain quality results. Design process are constrained which are difficult to apply and complex. Levels and factors will increase if number of experiments were increases. Taguchi technique uses a significance level of $95 \%$ with the help of design of orthogonal arrays. [17]. Three levels of proposals and three factors integrate the process parameters and the number of experiments as per table 2 .

Table 2: Design of control factors for Taguchi Analysis

\begin{tabular}{|c|c|c|c|}
\hline \multirow{2}{*}{ Level } & \multicolumn{3}{|c|}{ Factors } \\
\cline { 2 - 4 } & Load(N) & $\begin{array}{c}\text { Sliding } \\
\text { velocity } \\
(\mathrm{m} / \mathrm{s})\end{array}$ & $\begin{array}{c}\text { Sliding } \\
\text { distance(m) }\end{array}$ \\
\hline I & 20 & 1 & 500 \\
\hline II & 30 & 2 & 1000 \\
\hline III & 40 & 3 & 1500 \\
\hline
\end{tabular}

\section{RESULTS AND DISCUSSION}

Different milling hours along with the crystallite size were plotted in the XRD pattern for the ferritic ODS with aluminum content were shown in figure 3 . From the figure 3 it is revealed that peak broadening is influenced by the milling time. Powders after 20 hrs of milling broadening was attained for the peaks of ferrite phase $(\alpha-\mathrm{Fe})$. From the peak broadening of the milled alloy, XRD analysis shows the accomplishment of nano crystallite size. Solid solution is formed due to repetitive fracturing and cold welding of the mechanical alloyed powders [18]. The initial composition of the alloys contains lower content of yttrium and zirconium, so from the XRD pattern those corresponding peaks were not visible. Initial peak of the unmilled powder $(0 \mathrm{hr})$ shows individual peaks of ferrite and aluminum in the XRD pattern. Phase transformations of the powders are clearly evident for the MA powders from XRD. Crystallite sizes of the milled powders were found to be $8.5 \mathrm{~nm}$ through Debye's scherrer formula. Gibbs-Thompson effect is responsible for the disintegration of the solute atoms for to form a single phase solid solution with the addition of aluminum in ferritic steel [19]. As the milling time increases lattice stain increases and crystallite size reduces which results in the broadening of the peaks in XRD. Reduction of crystallite size and lattice stain increases can be observed from the figure 4 . After 20 hrs of milling the crystallite size of the powder decreases to $8.5 \mathrm{~nm}$ as shown in figure 4 and strain rate increases by $1.78 \%$.

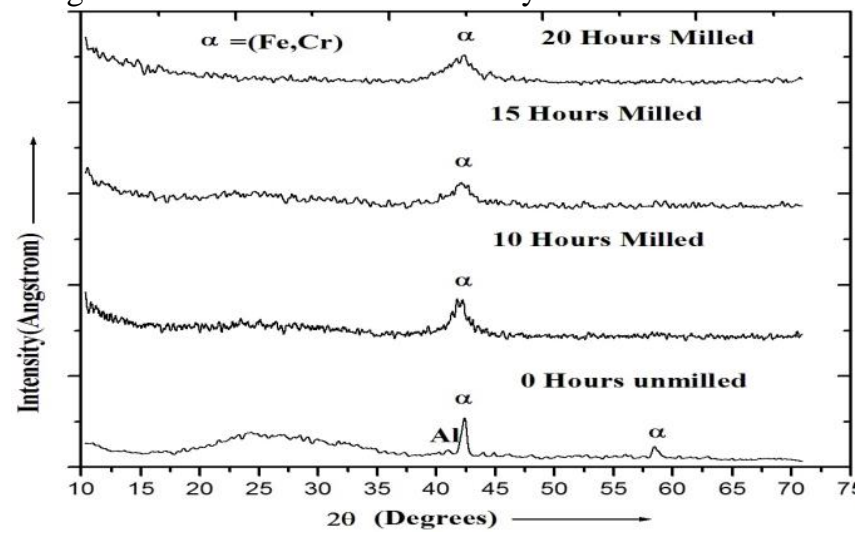

Fig.3 XRD patterns of mechanical alloyed alloy at different time intervals

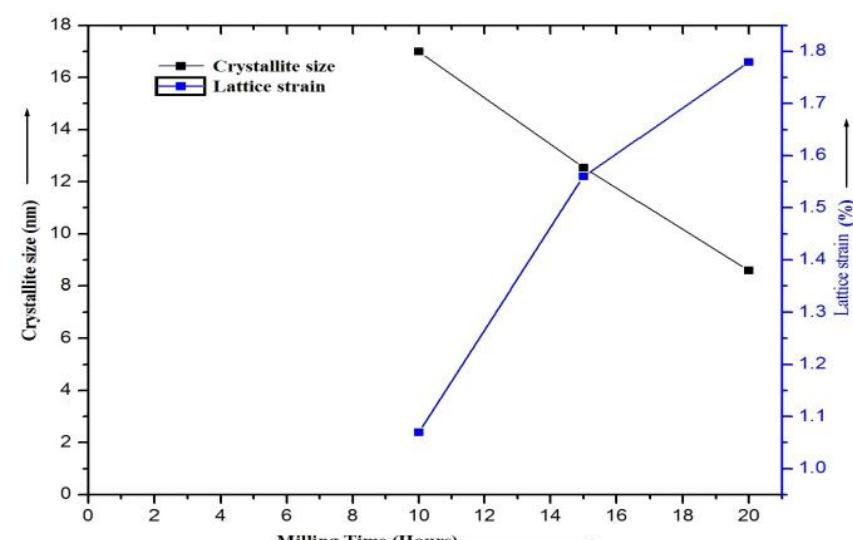

Fig.4 Relation between crystallite size and lattice strain of mechanical alloyed alloy

\section{Morphology using SEM for mechanical alloyed powders}

Powder morphology of the powders was taken for different time intervals for the mechanically alloyed powders which were carried out for 20 hrs as shown in figure 5. Identical shaped spherical pre-alloyed powders with jagged fine sized zirconia and yttria particles were shown in figure $5 \mathrm{a}$ for the un-milled powder. Flaky aluminum in little amount were also observed within the alloy. High impact between the powders and balls has undergone fracture [18].

Published By: 
Agglomeration was observed from the SEM morphology as the powders have undergone repeated cold welding where the particles are in micron size. Crystallite size has reduced micron to nano level due to longer milling hours (20 hrs).
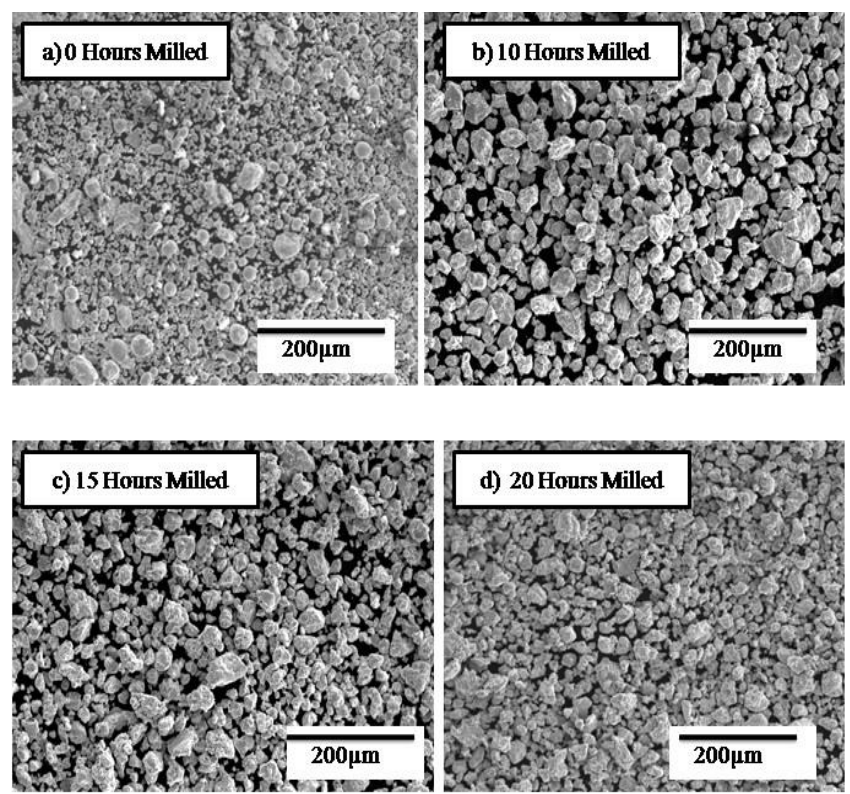

Fig .5 mechanically alloyed Powder SEM Morphology at different time intervals

\section{E. Vacuum hot pressed alloy of density and Microstructure}

The density of hot pressed alloy as shown in figure 6 . The sinter density was close to $98 \%$ of the theoretical density which was found to be about $7.35 \mathrm{~g} / \mathrm{cc}$. Figure 7 shows the polygonal ferrite structure microstructure of a hot pressed ODS alloy. The presence of aluminum marginal coarse ferrite grain was observed in the microstructure. Jeffries planimetric method was used to calculate the grain size number. A grain size number of 8 to 10 were exhibited by the hot pressed ODS steel as per ASTM standard. TEMEDS analysis of the alloy has shown the presence of ferrite with complex oxides, elemental mapping confirms the complex oxides consist of $\mathrm{Y}-\mathrm{Zr}-\mathrm{Al}-\mathrm{O}$ in the defined area as shown in figure 8 . Ferrite phase in the composition was stabilized by the elements such as Fe and chromium [20,21]. TEM analysis were carried out for the hot pressed ferritic ODS alloy to find out the presence of zirconium and yttria particles within the metal matrix. Uniform distribution of nano sized yttria and zirconium were present within the matrix with an average size of $15 \pm 8 \mathrm{~nm}$. Dislocation and grain boundary mitigation (zener pinning effect) were reduced as there is the presence of fine homogeneous stable nano sized ODS particles in the steel structure which results in increase in strength and decrease in wear rate at high temperatures which was reported by many researchers.

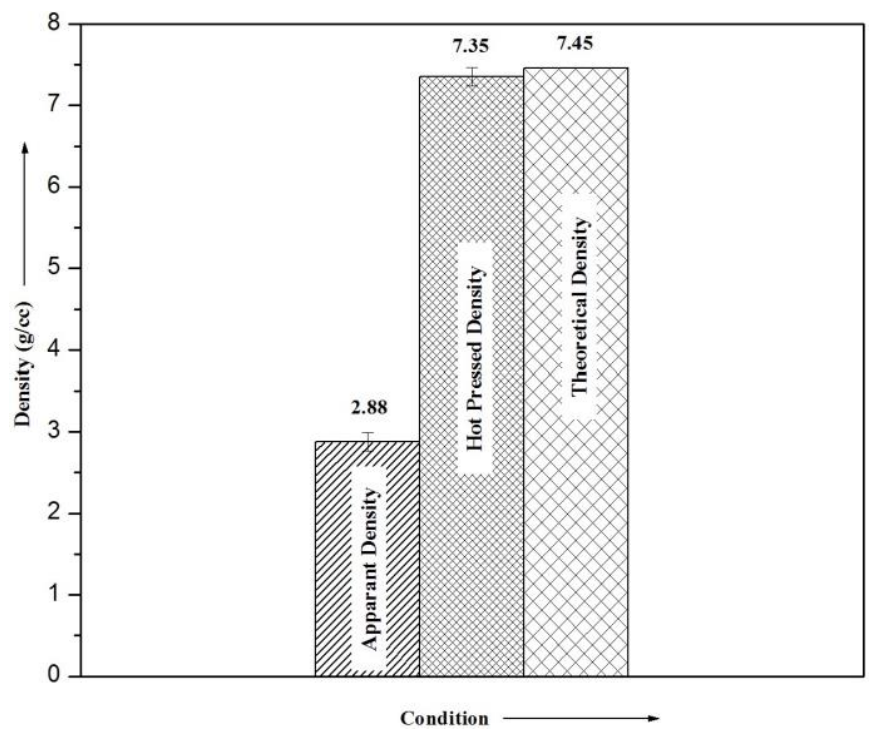

Fig.6 Density of hot pressed alloy

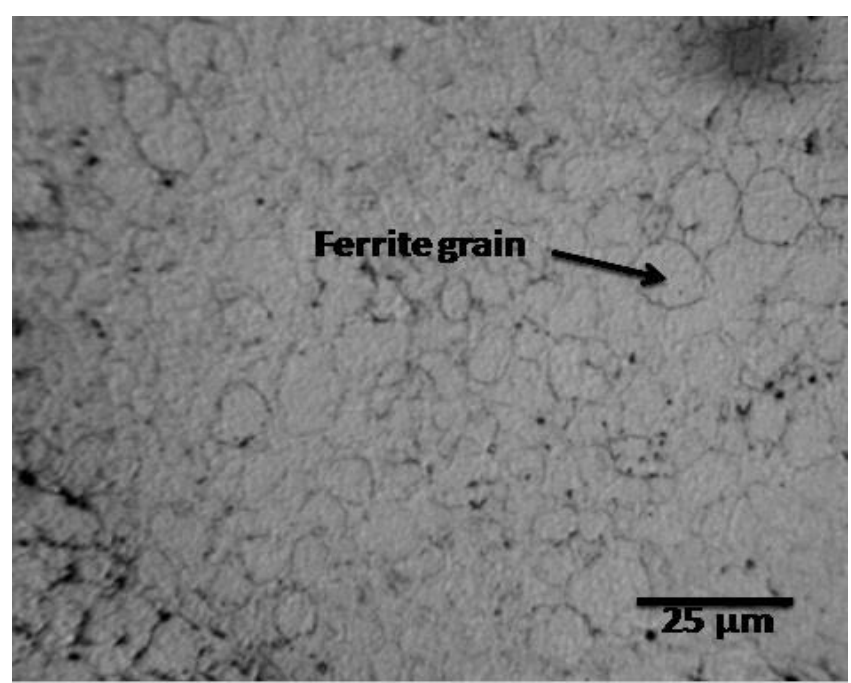

Fig7. Microstructures of Hot Pressed Ferritic ODS steel Alloy at 500X

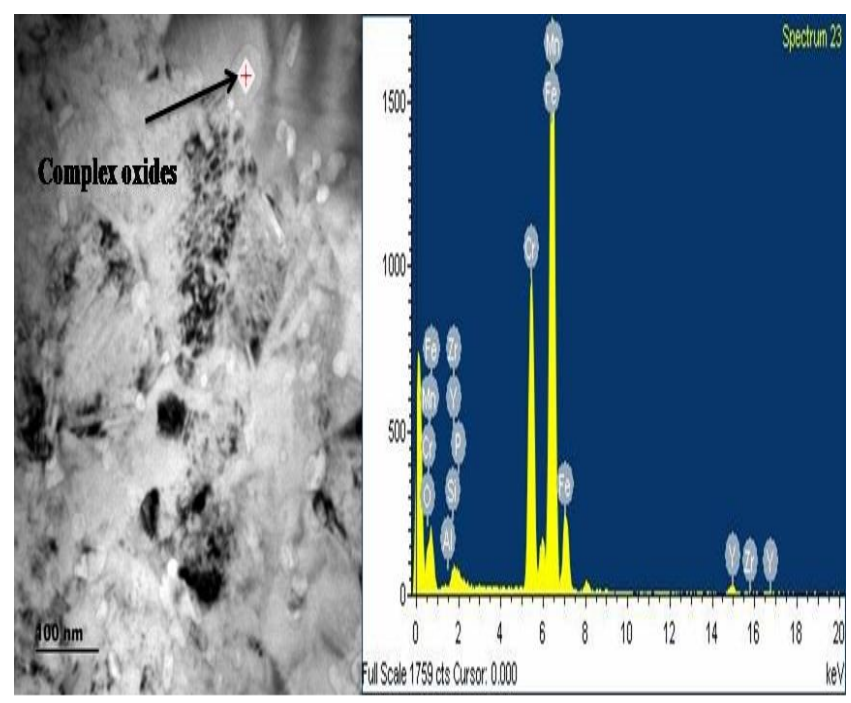

Fig.8 Micrograph of TEM-EDS analysis of hot pressed alloy

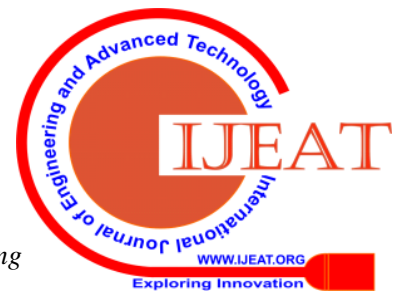




\section{F. Investigation of dry sliding wear behavior}

From the experimental data wear rate were investigated from the Taguchi L9 orthogonal array using significance test as shown in table 3 . Wear rate developmental model were evaluated using ANOVA. Accuracy of the wear rate was predicted by using derived regression model equation found from the experimental values. Optimum wear rate were determined from the input conditions. The signal to noise ratio $(\mathrm{S} / \mathrm{N})$ conversion was obtained as a utility of yield value which can be treated as excellence characteristics'. Smaller values are considered as a better quality characteristic which enhances the property of an objective function is wear rate as shown in equation 1.

$$
N=-10 \log \frac{1}{10} \sum_{i=1}^{n} y^{2}
$$

Minitab software 17.0 was used as a statistical tool to identify the optimum wear process parameter. Table 4 presents the input factors which were estimated for the wear rate using $\mathrm{S} / \mathrm{N}$ ratio values and delta values of the $\mathrm{S} / \mathrm{N}$ ratio were computed. A plot for response of $\mathrm{S} / \mathrm{N}$ ratio is shown in figure 9. Respective levels were plotted against output value independent parameter. Plot refers to mean response factor over the levels. High $\mathrm{S} / \mathrm{N}$ ratios were obtained for the creation of optimum quality with least variance. The lower wear rate preferred that can be obtained with values of process parameter such as sliding distance, sliding velocity and applied load were dogged as high as signal to noise ratio (S/N).A combination of level 2, level 1 and level 3 with respect to applied load, sliding distance and sliding velocity is minimum wear rate. Minimum wear rate is due to the high values of sliding distance, sliding velocity with load applied [22].

Table 3: L9 orthogonal array for Taguchi Analysis, output characteristics of $\mathrm{S} / \mathrm{N}$ ratios and measured values for Hot pressed wear rate of alloys

\begin{tabular}{|c|c|c|c|c|c|}
\hline \multirow{2}{*}{$\begin{array}{l}\text { All } \\
\text { oy } \\
\text { Id }\end{array}$} & \multicolumn{3}{|c|}{ Process parameters } & \multirow{2}{*}{$\begin{array}{l}\text { Experime } \\
\text { ntal value }\end{array}$} & \multirow{2}{*}{$\begin{array}{c}\begin{array}{c}\text { Signal/N } \\
\text { oise } \\
\text { Ratio }\end{array} \\
\text { Wear rate }\end{array}$} \\
\hline & $\begin{array}{c}\text { Load( } \\
\mathrm{N})\end{array}$ & $\begin{array}{l}\text { Slidin } \\
\text { g } \\
\text { veloci } \\
\text { ty } \\
(\mathrm{m} / \mathrm{s})\end{array}$ & $\begin{array}{c}\text { Sliding } \\
\text { distance } \\
\text { (m) }\end{array}$ & & \\
\hline 1 & 20 & 1 & 500 & 0.00764 & 42.3381 \\
\hline 2 & 20 & 2 & 1000 & 0.00547 & 45.2482 \\
\hline 3 & 20 & 3 & 1500 & 0.00478 & 46.4205 \\
\hline 4 & 30 & 1 & 1000 & 0.00575 & 44.8066 \\
\hline 5 & 30 & 2 & 1500 & 0.00354 & 49.0199 \\
\hline 6 & 30 & 3 & 500 & 0.00418 & 47.5765 \\
\hline 7 & 40 & 1 & 1500 & 0.00309 & 50.2008 \\
\hline 8 & 40 & 2 & 500 & 0.00613 & 44.2508 \\
\hline 9 & 40 & 3 & 1000 & 0.00312 & 50.1169 \\
\hline
\end{tabular}

Table 4: Response table for $\mathrm{S} / \mathrm{N}$ ratios Wear rate when smaller is better

\begin{tabular}{|c|c|c|c|}
\hline Level & Load(N) & $\begin{array}{c}\text { Sliding } \\
\text { velocity } \\
\text { (m/s) }\end{array}$ & $\begin{array}{c}\text { Sliding } \\
\text { distance(m) }\end{array}$ \\
\hline $\mathbf{1}$ & 44.67 & 45.78 & 44.72 \\
\hline $\mathbf{2}$ & 47.13 & 46.17 & 46.72 \\
\hline $\mathbf{3}$ & 48.19 & 48.04 & 48.55 \\
\hline Delta & 3.52 & 2.26 & 3.83 \\
\hline Rank & 2 & 3 & 1 \\
\hline
\end{tabular}

\section{G. Wear rate behavior of interaction plot}

Interaction plot for the applied load, sliding distance and sliding velocity as wear rate is shown in figure 10 . It is observed from the interaction plot that as there a decrease trend in wear rate an increase in sliding distance, load applied and sliding velocity. The decreasing in wear rate at high load, sliding distance and sliding velocity due to the presence of oxides are more effective by making pinning effect, where the dislocations are arrested at high temperature. Higher hardness with improved strength was attained for the vacuum hot pressed samples due to the addition of zirconium oxide, aluminum and yttrium oxide through Hall-Petch strengthening effect [25]. More wear rate were development as a result of low sliding velocity and sliding distance [20,23]. The sliding distance percentage contribution level was more than the applied load. From the three dimensional (3-D) outline plot of wear rate against applied load and sliding distance vs sliding velocity are shown in figure 11 with its respective level of wear rate. In figure 12 probability plot distribution is normal straight line against wear rate. Standard deviation $(\sigma)$ and mean zero were significantly and normally distributed. Representation of normal probability plot was graphically represented as per the central limit theorem. The points were nearer to the fitted line, particularly towards the middle group, which demonstrates most important significance on yield erratic represented by the estimated factor. Similar kind of results were also observed in the previous study [24]. 


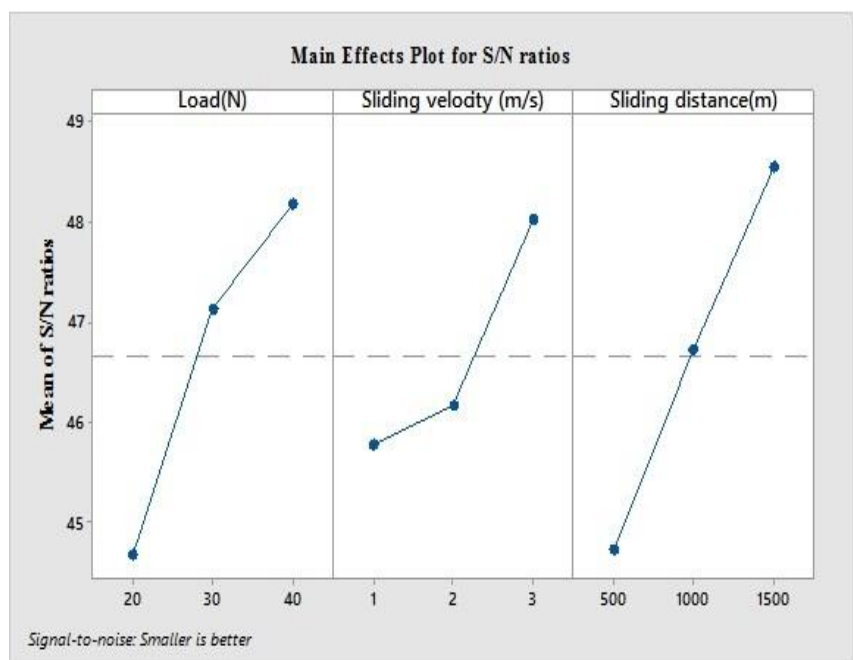

Fig.9 Main Effects plot of response for $\mathrm{S} / \mathrm{N}$ ratios-Wear rate

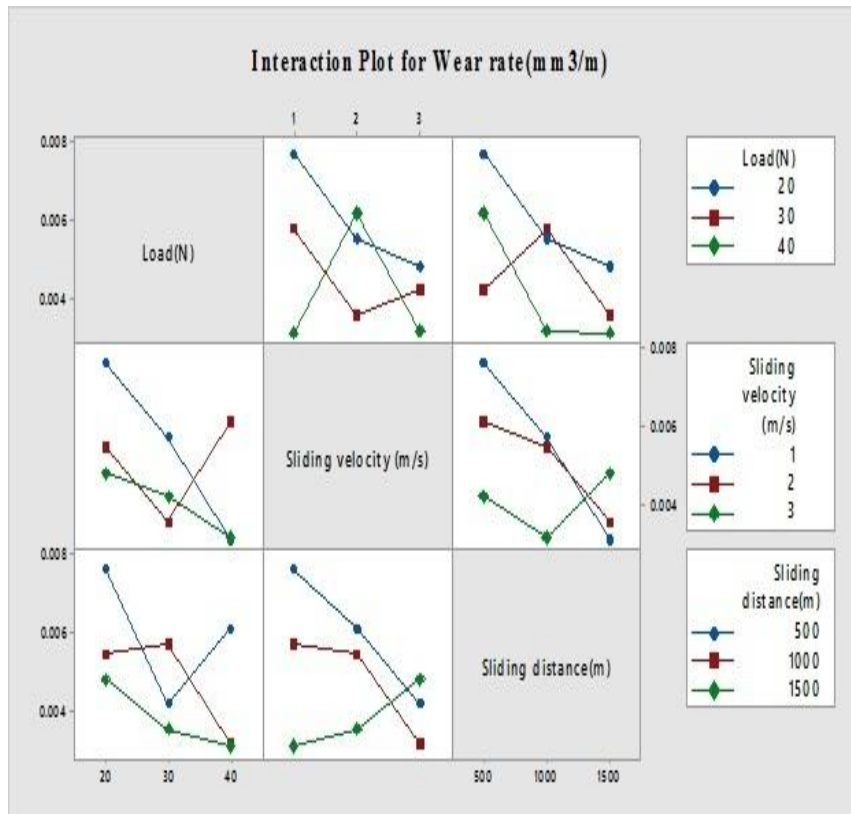

Fig.10 graphs depicts the behavior of wear rate through Interaction plot

3D Scatterplot of Load(N) vs Sliding velocity vs Sliding distance

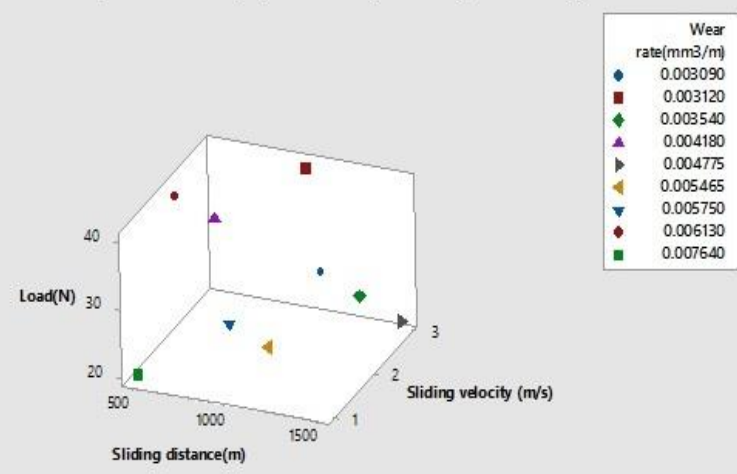

Fig.11 3-D Contour Plot of wear rate vs applied load, sliding distance and sliding velocity



Fig.12 Graphs depicts the Normal probability plot for wear rate

\section{H. Multiple Linear Regression Model}

Correlation regarding factors and response is found out using multiple linear regression equation.

Regression co-efficient (R2) which is $96.71 \%$ is in good agreement with the adjusted R2 value $94.48 \%$ for the wear rate.

Wear rate regression equation as shown in equation 2

Wear rate $(\mathrm{mm} 3 / \mathrm{m})=0.01127-0.000092 \operatorname{Load}(\mathrm{N})$ 0.000734 Sliding velocity $(\mathrm{m} / \mathrm{s})$

- 0.000002 Sliding distance (m)

Inspecting the parameters through ANOVA gives more importance to the process factor. MINITAB 17.0 was used to execute the analysis of variance (ANOVA). From the analysis of variance table 5 were identified the pvalue significance of each parameter. A highly significant parameter can be considered if the p-value is less than 0.05 . The P-value of sliding distance is found to be 0.05 which are having a high significant level of 95\%. It was observed that the sliding distance is the majority influence factor to raise the minimum wear rate followed by applied load and sliding velocity. Analysis of variance ( ANOVA) and $\mathrm{S} / \mathrm{N}$ ratio results are having minimal deviation to each other whereas the contribution in percentage of the process parameters are $14.32 \%, 36.12 \%$ and $32.17 \%$ for sliding velocity, sliding distance and applied load respectively for the wear rate [24].

Table 5: ANOVA analysis for Wear rate

\begin{tabular}{|c|c|c|c|c|c|c|c|}
\hline \multicolumn{7}{|c|}{ Wear rate } \\
\hline Factors & $\begin{array}{c}\text { D } \\
\text { F }\end{array}$ & $\begin{array}{c}\text { Seq } \\
\text { SS }\end{array}$ & $\begin{array}{c}\text { Adj } \\
\text { SS }\end{array}$ & $\begin{array}{c}\text { Adj } \\
\text { MS }\end{array}$ & $\begin{array}{c}\text { F- } \\
\text { val } \\
\text { ue }\end{array}$ & $\begin{array}{c}\text { P- } \\
\text { value }\end{array}$ & $\begin{array}{c}\text { PC } \\
\%\end{array}$ \\
\hline Load(N) & 2 & $\begin{array}{c}19.5 \\
86\end{array}$ & $\begin{array}{c}19.5 \\
86\end{array}$ & $\begin{array}{c}9.79 \\
3\end{array}$ & $\begin{array}{c}1.8 \\
5\end{array}$ & $\begin{array}{c}0.035 \\
1\end{array}$ & $\begin{array}{c}32 . \\
17\end{array}$ \\
\hline $\begin{array}{c}\text { Sliding } \\
\text { velocity } \\
\text { (m/s) }\end{array}$ & 2 & $\begin{array}{c}8.72 \\
1\end{array}$ & $\begin{array}{c}8.72 \\
1\end{array}$ & $\begin{array}{c}4.36 \\
1\end{array}$ & $\begin{array}{c}0.8 \\
2\end{array}$ & $\begin{array}{c}0.044 \\
8\end{array}$ & $\begin{array}{c}14 . \\
32\end{array}$ \\
\hline
\end{tabular}




\begin{tabular}{|c|c|c|c|c|c|c|c|}
\hline & & & & & & & \\
\hline $\begin{array}{c}\text { Sliding } \\
\text { distance } \\
\text { (m) }\end{array}$ & 2 & $\begin{array}{c}21.9 \\
65\end{array}$ & $\begin{array}{c}21.9 \\
65\end{array}$ & $\begin{array}{c}10.9 \\
83\end{array}$ & $\begin{array}{c}2.0 \\
7\end{array}$ & $\begin{array}{c}0.032 \\
53\end{array}$ & $\begin{array}{c}36 . \\
12\end{array}$ \\
\hline Error & 2 & $\begin{array}{c}10.5 \\
93\end{array}$ & $\begin{array}{c}10.5 \\
93\end{array}$ & $\begin{array}{c}5.29 \\
6\end{array}$ & & & $\begin{array}{c}17 . \\
4\end{array}$ \\
\hline Total & 8 & $\begin{array}{c}60.8 \\
65\end{array}$ & & & & & 100 \\
\hline
\end{tabular}

SS-Sum of squared deviation, MS-Mean squared deviation, DF-Degree of freedom, P-Probability of significance, F- Fisher's F ratio, PC-Percentage of contribution.

\section{Analysis of wear debris through SEM-EDS}

Oxides layers were observed on the surface due to high temperature wear analysis along with the application of load and sliding distance. Wear rate in decrease trend were observed due to the formation of oxides on the surface. Formation of debris mechanism is dependent on sliding distance and load applied. In the current study due to the formation of oxide scales sliding distance increases as the wear rate decreases. This is evident through

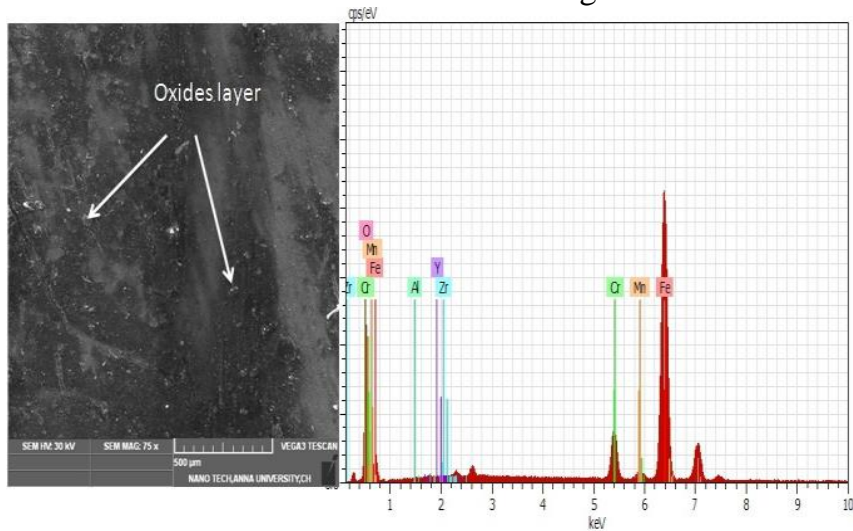

Fig.13 SEM and EDS analysis of wear debris at sliding distance $1500 \mathrm{~m}$, applied load $40 \mathrm{~N}$ and sliding velocity $3 \mathrm{~m} / \mathrm{s}$

scanning electron microscopy - energy dispersive $\mathrm{X}$ ray spectroscopy (SEM-EDS) as shown in figure 13. High chromium stainless steel were performed wear analysis in between 200 to $400^{\circ} \mathrm{C}$, formation of $(\mathrm{Fe}, \mathrm{Cr}, \mathrm{Al})$ oxides scale on their surface are responsible for reducing the wear rate. Sulivan et. al reported that formation $\alpha-\mathrm{Fe} 2 \mathrm{O} 3$ take place in between 200 to $450^{\circ} \mathrm{C}$, likewise the formation $\mathrm{Fe} 3 \mathrm{O} 4$ in between 450 to $600^{\circ} \mathrm{C}$. At higher temperature more than $600^{\circ} \mathrm{C}$ the formation of $\mathrm{FeO}$ scales are responsible for lower wear rate $[25,26]$.

\section{J. Mechanical properties of hot pressed alloy}

Tables 6 has shown the nano intended behavior such as hardness, young's modulus of $17 \mathrm{Cr}$ ferritic ODS steels hot pressed at $1170^{\circ} \mathrm{C}$ with a pressure level of $60 \mathrm{MPa}$. Measurement of hardness using Nano indentation test were shown in figure 14. From the results it is observed that young's modulus of this hot pressed ODS steel is $46 \%$ higher than the conventional ferritic steels. For the attainment of higher hot pressed density of $98 \%$ addition of yttrium, zirconium oxide particles are most responsible factor and also higher sintering pressure. Similarly nano intended hardness and Rockwell hardness numbers are 22 GPa and 64 HRA respectively. Karak et.al investigated the similar kind of investigation on ferritic ODS steels were developed through hot isostatic pressing at different temperatures such $600^{\circ} \mathrm{C}, 800^{\circ} \mathrm{C}$ and $1000^{\circ} \mathrm{C}$. Higher sintering temperature lead to higher density, hardness and modulus of elasticity, lower co-efficient of friction due to faster atomic diffusion [11] .Wear resistance of the above said steel is calculated from the linear equation 3. Calculation of wear properties of $17 \mathrm{Cr}$ ferritic ODS were done with different loads, varying sliding distance and sliding velocities. Identification of process parameter for wear rate were done for the material with the help of optimization technique which has undergone least wear rate, with application of load applied, sliding velocity and sliding distance of $0.00239 \mathrm{~mm} 3 / \mathrm{m}, 40 \mathrm{~N}, 3 \mathrm{~m} / \mathrm{s}$ and $1500 \mathrm{~m}$ respectively using Taguchi analysis. It can be observed from the experimental studies that the material has undergone oxidation wear mechanism.

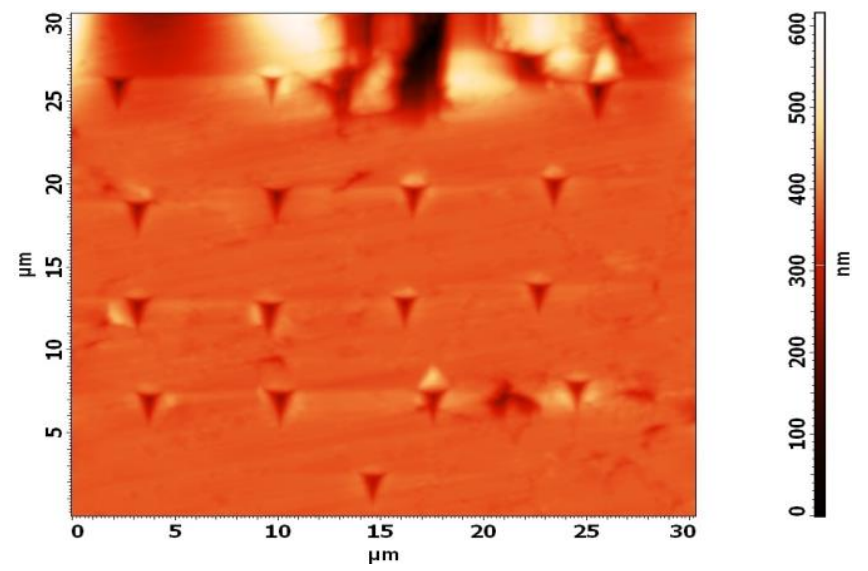

Fig.14 Measurement of hardness using Nano indentation test

Table 6: Mechanical properties of Vacuum hot pressed

\begin{tabular}{|c|c|c|c|c|c|}
\hline \multicolumn{6}{|c|}{ alloy } \\
\hline $\begin{array}{l}\text { Allo } \\
\text { y Id }\end{array}$ & $\begin{array}{c}\text { Hardne } \\
\text { ss } \\
\text { (GPa) }\end{array}$ & $\begin{array}{l}\text { Young' } \\
\text { s } \\
\text { Modul } \\
\text { us } \\
\text { (GPa) }\end{array}$ & $\begin{array}{l}\text { Wear } \\
\text { resistan } \\
\text { ce (1/K) }\end{array}$ & $\begin{array}{c}\text { Rockw } \\
\text { ell } \\
\text { hardne } \\
\text { ss } \\
\text { (HRA) }\end{array}$ & $\begin{array}{c}\text { Avera } \\
\text { ge Co - } \\
\text { efficie } \\
\text { nt of } \\
\text { frictio } \\
\text { n }\end{array}$ \\
\hline I & 22 & 278 & 218.15 & 64 & 0.5 \\
\hline
\end{tabular}

Friction co-efficient and wear resistance are dependent on the material properties, surface topography, process parameters like load, sliding distance, temperature, sliding velocity, environment and are not characteristic material properties. The wear rate connecting to the increasing volume loss per sliding distance component and wear resistance were calculated from the linear equation (3). 
$\mathrm{Q}=\frac{V}{S}=k * \frac{F \mathrm{~N}}{H}$

Where $\mathrm{H}$ is the hardness of the hot pressed alloy, $\mathrm{K}$ is the wear co-efficient of the alloy which is a non dimensionless whose value is less than $1, \mathrm{~S}$ is the sliding distance, $\mathrm{FN}$ is the applied normal load, $\mathrm{V}$ is denoted as cumulative volume loss and $\mathrm{Q}(\mathrm{mm} 3 / \mathrm{m})$ is the measurement of wear rate. In universal, the wear resistance is defined as $1 / \mathrm{K}$ [27].

\section{CONFIRMATION EXPERIMENT}

From the table 4 and figure 9 optimum wear process parameters were identified for the experimental results. To obtain minimum wear rate the parameters optimized were sliding distance of $1500 \mathrm{~m}, 40 \mathrm{~N}$ of applied load and sliding velocity of $3 \mathrm{~m} / \mathrm{s}$. From table 7 of the experimental results shows the confirmation test of the carried out test. From the regression equation (2) wear rate values were calculated which are nearly same as the experimental values with least error of $( \pm 0.420 \%)$. Prediction of wear rate for $17 \mathrm{Cr}$ ferritic ODS steels were obtained from the regression equation. Wear rate comparison between predicted and experimental results were shown in table 8 . Outcomes are in high-quality conformity with both experimental and analytical values through Taguchi approach.

Table 7: Parameters used in the confirmation wear test

\begin{tabular}{|c|c|c|c|}
\hline \multirow{2}{*}{$\begin{array}{c}\text { Alloy } \\
\text { ID }\end{array}$} & \multicolumn{3}{|c|}{ Factors } \\
\cline { 2 - 4 } & Load(N) & $\begin{array}{c}\text { Sliding velocity } \\
(\mathrm{m} / \mathrm{s})\end{array}$ & $\begin{array}{c}\text { Sliding } \\
\text { distance(m) }\end{array}$ \\
\hline I & 40 & 3 & 1500 \\
\hline
\end{tabular}

Table 8: Confirmation wear rate results compared with regression model equation

\begin{tabular}{|c|c|c|c|}
\hline $\begin{array}{c}\text { Alloy } \\
\text { ID }\end{array}$ & $\begin{array}{c}\text { Experimental wear } \\
\text { rate }\left(\mathrm{mm}^{3} / \mathrm{m}\right)\end{array}$ & $\begin{array}{c}\text { Model equation } \\
\text { wear rate } \\
\left(\mathrm{mm}^{3} / \mathrm{m}\right)\end{array}$ & Error(\%) \\
\hline I & 0.00239 & 0.00238 & 0.420 \\
\hline
\end{tabular}

\section{CONCLUSION}

- Determination of the minimum wear rate of $17 \mathrm{Cr}$ ferritic ODS steels are successfully carried out using design of experiments; from the results observed that sliding distance is a major influencing factor for the minimum wear rate.

- From the experimental that the most excellent parametric mixture of applied load, sliding velocity and sliding distance from the results of signal to noise ratio and analysis of variance with values of $40 \mathrm{~N}, 3 \mathrm{~m} / \mathrm{s}$ and 1500 $\mathrm{m}$ respectively has a minimum wear rate of 0.00239 $\mathrm{mm}^{3} / \mathrm{m}$ when compared to other processing parameters.

- Mathematically modeling using regression investigation was used to find out the variation in process parameters and results were certified by confirmation test. Taguchi approach is a powerful method for calculating the minimum wear rate using regression equation.
- Minimum wear rate were obtained without conducting experiments with the help of Taguchi approach and these developed model will be useful for industrial applications such as automobile exhaust valves, gas turbines, nuclear reactors etc.

\section{ACKNOWLEDGMENT}

The authors would like to take this opportunity to express gratitude the Hon'ble Chairman of Vel Tech Rangarajan Dr. Sagunthala R \& D Institute of science and Technology, Chennai, India for provided that facilities in the Research Park and allowing us to publish this technical article. Moreover authors would like express their sincere gratefulness to M/S Sandvik for supplying $430 \mathrm{~L}$ pre alloyed FSS powder to carry out this research work.

\section{REFERENCES}

1. R. Klueh, K. Ehrlich, F. Abe, Ferritic/martensitic steels: promises and problems, Journal of nuclear materials, 191, 116124 (1992)

2. H.Y. Kim, O.Y. Kwon, J. Jang, S.H. Hong, Modification of anisotropic mechanical properties in recrystallized oxide dispersion strengthened ferritic alloy, Scripta materialia, 54(9), 1703-1707 (2006)

3. S. Noh, R. Kasada, A. Kimura, S.H.C. Park, S. Hirano Microstructure and mechanical properties of friction stir processed ODS ferritic steels, Journal of Nuclear Materials, 417(1-3), 245-248 (2011)

4. D.A. McClintock, M.A. Sokolov, D.T. Hoelzer, R.K. Nanstad, Mechanical properties of irradiated ODS-EUROFER and nanocluster strengthened 14YWT, Journal of Nuclear Materials, 392(2), 353-359 (2009)

5. L. Guo, C. Jia, B. Hu, H. Li, Microstructure and mechanical properties of an oxide dispersion strengthened ferritic steel by a new fabrication route, Materials Science and Engineering: A, 527(20), 5220-5224 (2010) .

6. K. Asano, Y. Kohno, A. Kohyama, T. Suzuki, H. Kusanagi, Microstructural evolution of an oxide dispersion strengthened steel under charged particle irradiation, Journal of Nuclear Materials, 155, 928-934 (1988)

7. M. Li, Z. Zhou, P. He, L. Liao, Y. Xu, C. Ge, Microstructure and mechanical property of $12 \mathrm{Cr}$ oxide dispersion strengthened ferritic steel for fusion application, Fusion Engineering and Design, 85(7-9), 1573-1576 (2010)

8. R. Shashanka, D. Chaira, Effect of sintering temperature and atmosphere on nonlubricated sliding wear of nano-yttriadispersed and yttria-free duplex and ferritic stainless steel fabricated by powder metallurgy, Tribology Transactions, 60(2), 324-336 (2017)

9. P. He, M. Klimenkov, R. Lindau, A. Möslang, Characterization of precipitates in nano structured $14 \% \mathrm{Cr}$ ODS alloys for fusion application, Journal of Nuclear Materials, 428(1-3), 131-138 (2012)

10. Z. Oksiuta, N.L. Baluc, Role of $\mathrm{Cr}$ and $\mathrm{Ti}$ contents on the microstructure and mechanical properties of ODS ferritic steels, Advanced Materials Research, 2009, Trans Tech Publ, pp 308312

11. S. Karak, C. Vishnu, Z. Witczak, W. Lojkowski, J.D. Majumdar, I. Manna, Studies on wear behavior of nano-Y2O3 dispersed ferritic steel developed by mechanical alloying and hot isostatic pressing, Wear, 270(1-2), 5-11 (2010) 
12. E. Ruiz-Navas, N. Anton, E. Gordo, R. Navalpotro, F. Velasco, Wear behavior of a ferritic stainless steel with carbides manufactured through powder metallurgy, Journal of materials engineering and performance, 10(4), 479-483 (2001)

13. W. Tuckart, M. Gregorio, L. Iurman, Sliding wear of plasma nitrided AISI 405 ferritic stainless steel, Surface Engineering, 26(3), 185-190 (2010)

14. C. Suryanarayana, Mechanical alloying and milling, Progress in materials science, 46(1-2), 1-184 (2001)

15. C. Suryanarayana, E. Ivanov, V. Boldyrev, The science and technology of mechanical alloying, Materials Science and Engineering: A, 304, 151-158 (2001)

16. G. Dharmalingam, R. Mariappan, M.A. Prasad, Optimization of wear process parameters on 16-Cr Ferritic ODS steel through Taguchi approach, Materials Today: Proceedings, (2019)

17. J. Udaya Prakash, S. Jebarose Juliyana, M. Saleem, T. Moorthy, Optimisation of dry sliding wear parameters of aluminium matrix composites (356/B4C) using Taguchi technique, International Journal of Ambient Energy, 1-3 (2018)

18. A. García-Junceda, M. Campos, N. García-Rodríguez, J.M. Torralba, On the role of alloy composition and sintering parameters in the bimodal grain size distribution and mechanical properties of ODS ferritic steels, Metallurgical and Materials Transactions A, 47(11), 5325-5333 (2016)

19. S.K. Karak, J.D. Majumdar, Z. Witczak, W. Lojkowski, Ł. Ciupiński, K. Kurzydłowski, I. Manna, Evaluation of microstructure and mechanical properties of nano- $\mathrm{Y}_{2} \mathrm{O}_{3}$ dispersed ferritic alloy synthesized by mechanical alloying and consolidated by high-pressure sintering, Metallurgical and Materials Transactions A, 44(6), 2884-2894 (2013)

20. Y. Xia, X. Wang, Z. Zhuang, Q. Sun, T. Zhang, Q. Fang, T. Hao, C. Liu, Microstructure and oxidation properties of $16 \mathrm{Cr}-$ 5Al-ODS steel prepared by sol-gel and spark plasma sintering methods, Journal of Nuclear Materials, 432(1-3), 198-204 (2013)

21. R. Mariappan, M.A. Prasad, G. Dharmalingam, D. Sivaprakasham, Microstructure and Mechanical Properties of Hot-Pressed 21-4N Oxide-Dispersion-Strengthened Austenitic Stainless Steels, Metallography, Microstructure, and Analysis, 7(5), 578-586 (2018)

22. M. Yousefieh, M. Shamanian, A. Arghavan, Analysis of design of experiments methodology for optimization of pulsed current GTAW process parameters for ultimate tensile strength of UNS S32760 welds, Metallography, Microstructure, and Analysis, 1(2), 85-91 (2012)

23. P.K. Kumar, N.V. Sai, A.G. Krishna, Influence of Sintering Conditions on Microstructure and Mechanical Properties of Alloy 218 Steels by Powder Metallurgy Route, Arabian journal for science and engineering, 43(9), 4659-4674 (2018)

24. M. Yousefieh, M. Shamanian, A. Saatchi, Optimization of experimental conditions of the pulsed current GTAW parameters for mechanical properties of SDSS UNS S32760 welds based on the Taguchi design method, Journal of materials engineering and performance, 21(9), 1978-1988 (2012)

25. J. Sullivan, T. Quinn, D. Rowson, Developments in the oxidational theory of mild wear, Tribology International, 13(4), 153-158 (1980)

26. A. Vijayanand, S. Natarajan, K. Ramkumar, S. Sundararajan, Optimization and dry sliding wear behaviour of spray coated MoS 2 on automotive ball joints through response surface methodology, Materials Research Express, (2018) .

27. J. Bressan, D. Daros, A. Sokolowski, R. Mesquita, C. Barbosa, Influence of hardness on the wear resistance of 17-4 $\mathrm{PH}$ stainless steel evaluated by the pin-on-disc testing, Journal of materials processing technology, 205(1-3), 353-359 (2008) .

\section{AUTHORS PROFILE}

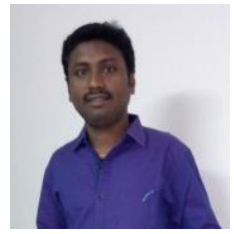

G. Dharmalingam obtained his Master Degree from Anna University, Chennai. He is pursuing currently doctoral research studies in the area of material science and metallurgy and powder metallurgy at Vel Tech Rangarajan Dr.Sagunthala R\&D Institute of science and Technology, Chennai. His area of research includes Optimization Techniques, composite materials and Material characterization.

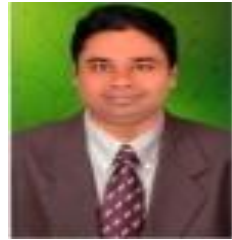

Dr. Prabhukumar Sellamuthu obtained his $\mathrm{PhD}$ from Deakin University, Australia in the field of Metallurgical and Materials Engineering. Finished his Masters in IIT Madras and Bachelors in Anna University, Chennai. His area of research includes Material Characterization, Mechanical Testing of Materials and Material Processing. Currently working as an Assistant Professor in the Departmen of Mechanical Engineering in Vel Tech Rangarajan Dr.Sagunthala R\&D Institute of science and Technology, Chennai. 